\title{
Neoformación en cara lateral externa de pie izquierdo
}

\section{Neoformation in the external lateral aspect of the left foot}

\author{
Angélica Villanueva-Otamendi, ${ }^{*}$ Maribet González-González, ${ }^{\ddagger}$ Pamela Orozco-Olguín
}

\section{CASO CLÍNICO}

Se trata de un hombre de 56 años de edad, originario y residente de la Ciudad de México, sin antecedentes personales patológicos de importancia. Acude por presentar, desde hace tres años, una dermatosis localizada a la extremidad inferior izquierda, la que afectaba la cara lateral externa del dorso del pie, unilateral. Estaba constituida por una neoformación no bien definida, de 1.5 $\times 0.8 \mathrm{~cm}$, eritematosa, lobulada, pediculada, de bordes bien delimitados, superficie anfractuosa, con algunas hendiduras y leve escama blanquecina, adherente. De evolución crónica y asintomática (Figuras 1 y 2). A la dermatoscopía se observa neoformación exofítica, con vasos tortuosos e hiperqueratosis (Figura 3).

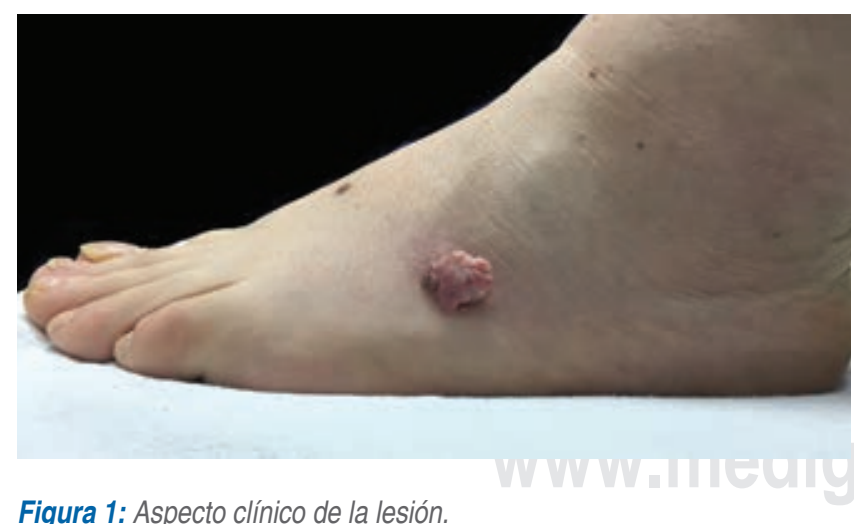

Figura 1: Aspecto clínico de la lesión.

\footnotetext{
* Dermatóloga.

‡ Dermatopatóloga.

Centro Dermatológico «Dr. Ladislao de la Pascua», SSCDMX.
}

Con los datos proporcionados, ¿cuál es su diagnóstico?

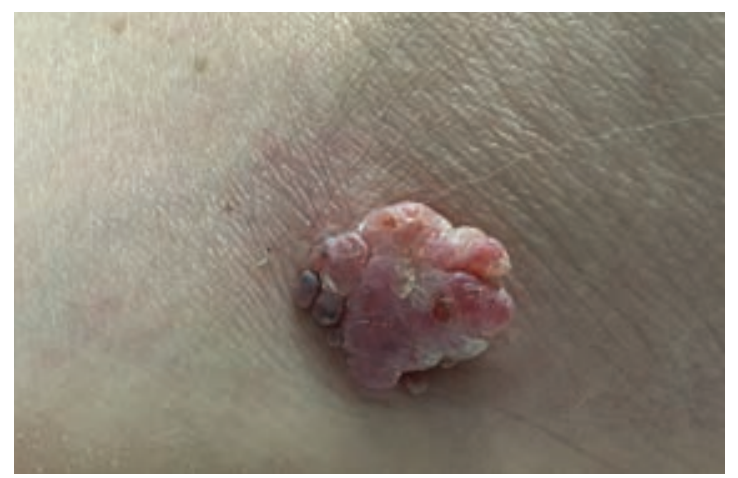

Figura 2: Lesión a mayor acercamiento.

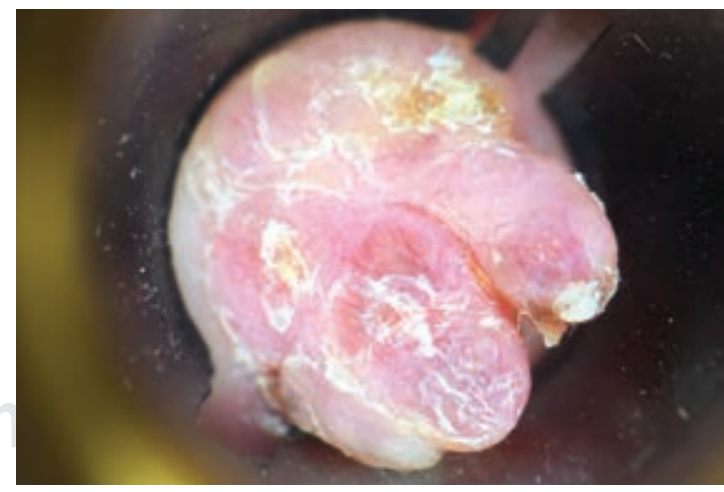

Figura 3: Imagen dermatoscópica de la lesión.

Citar como: Villanueva-Otamendi A, González-González M, Orozco-Olguín P. Neoformación en cara lateral externa de pie izquierdo. Rev Cent Dermatol Pascua. 2021; 30 (2): 101-104. https://dx.doi.org/10.35366/101181 
Villanueva-Otamendi A y cols. Neoformación en pie izquierdo

\section{CARCINOMA BASOCELULAR DE TOPOGRAFÍA ATÍPICA}

\author{
Introducción
}

El carcinoma basocelular (CBC) es el tumor maligno más frecuente de la piel, sobre todo en sujetos de raza blanca. Representa $65-75 \%$ de todos los carcinomas. Su crecimiento es lento y raramente da metástasis. ${ }^{1-3}$ Entre los posibles factores etiopatológicos se han citado los siguientes: pertenecer a los fototipos cutáneos I y II, exposición crónica al arsénico, uso de psoralenos, herencia, traumatismos, estados de inmunosupresión sistémica, ser portador de úlceras crónicas de pierna, de nevo sebáceo, por quemaduras térmicas y, desde luego, la exposición excesiva a la luz ultravioleta. Este último factor ha sido aceptado universalmente como el más relevante, en especial si se lleva a cabo durante las primeras décadas de la vida. ${ }^{4-9}$

Lo anterior justifica que la mayoría de los carcinomas basocelulares se localicen en zonas fotoexpuestas de cabeza y cuello, representando $90 \%$ de todos los casos. ${ }^{10}$ El diagnóstico de certeza del CBC se establece mediante biopsia incisional para luego llevar a cabo el tratamiento correspondiente; se considera como terapéutica ideal la exéresis completa del tumor. Es considerado como tumor de buen pronóstico, aunque la posibilidad de recaída local requiere seguimiento estricto de forma periódica. ${ }^{11-13}$

Se han publicado casos en los que la ubicación de este tumor no se relaciona con áreas expuestas a la radiación solar, y por ello se consideran localizaciones atípicas. ${ }^{10}$

Son considerados carcinomas basocelulares de localización infrecuente aquellos que se ubican, por ejemplo, en el borde lateral de pie, en el pliegue interglúteo, a nivel de genitales, perineal, perianal, periungueal, en abdomen, axila, labio superior o inferior de la boca. Algunos autores consideran que estos tumores de localización no habitual se presentan en un porcentaje menor a 0.22 del total de los epiteliomas basocelulares. ${ }^{14}$ Rahbari y Mehregan, en 1979, detectaron en total 2,126 casos, $82.92 \%$ en cabeza y cuello, $9.84 \%$ en tórax anterior y posterior, $6.76 \%$ en miembro superior e inferior y $0.48 \%$ en genitales y región perianal. ${ }^{15}$

En el estudio realizado por la Dra. Alejandra Abeldaño y colaboradores, en el año 2010, se estudiaron 611 pacientes: 319 mujeres (52.2\%) y 292 varones $(47.8 \%)$, con una media de edad de 68.39 años (rango: 19-98 años). La cantidad total de CBC fue de 873 tumores. El promedio de neoformaciones por paciente fue 1.43 (mínimo 1, máximo 10). La proporción de CBC por sitio o ubicación anatómica fue: en cabeza y cuello $65.4 \%$ y en extremidades inferiores de $5 \%$. De 873 tumores, sólo se detectaron tres ubicados en el pie, lo cual corresponde a $0.3 \%{ }^{16}$

Es difícil comparar los hallazgos de los diferentes estudios de series de casos de CBC de localización infrecuente $o$ atípica por la falta de consenso en cuanto a la definición exacta de «infrecuente» o «atípico». En la literatura argentina, el trabajo más extenso fue publicado por Di Fabio y colaboradores, ${ }^{10}$ en 1986, quienes encontraron $17.78 \%$ de CBC de este tipo. Estos autores definen como tumores de localización infrecuente aquellos ubicados en sitios distintos de cabeza y cuello. En una revisión de un periodo de seis años detectaron en total 602 tumores, de los que $82.22 \%$ tenía localización cefálica. Mientras que $17.78 \%$, ubicado en otros sitios, mostró la siguiente distribución: $4.2 \%$ en tronco anterior, $4.32 \%$ en espalda, $0.83 \%$ en abdomen, $3.32 \%$ en área lumbosacra, $0.50 \%$ en genitales, $2.33 \%$ en extremidades superiores y $2.16 \%$ en extremidades inferiores.

En otro estudio, Dagatti y colaboradores ${ }^{13}$ consideran como localizaciones frecuentes cabeza, cuello, tronco y extremidades, con $1.12 \%$ correspondiente a CBC de localización infrecuente (semimucosa de labio inferior, axila, mama, ombligo, región inferior de abdomen, zona crural, escroto, labio mayor de vulva, pliegue interglúteo, fosa iliaca y borde lateral de pie).

Ninguno de los trabajos antes descritos realiza análisis estadístico de los datos que avalen el uso del término «localización infrecuente» para CBC.

Analizando cada área anatómica en particular, podemos observar que la frecuencia de epiteliomas a nivel de extremidades inferiores oscila entre $1.5 \mathrm{y}$ $13.5 \%$, según distintos autores. Pearson y colaboradores, en un estudio de 4,336 pacientes con CBC en distintas localizaciones, encontraron que 89 mujeres $(2.05 \%)$ y 33 hombres $(0.76 \%)$ eran portadores de $\mathrm{CBC}$ en extremidades inferiores. Esta predominancia estadísticamente significativa en mujeres también es señalada por otros autores. Las causas se atribuyen a mayor exposición solar con fines estéticos y laborales, y a los cambios en el hábito del vestir. ${ }^{17,18}$ En el estudio de la Dra. Abeldaño y colaboradores, el porcentaje de CBC en miembros inferiores fue de 44/873 (5\%).

La mayoría de los autores coinciden en que el subtipo histológico más frecuente es el superficial. Las variantes histopatológicas fueron similares para 
superficiales (34.1\%), lobulados (31.8\%), en menor proporción lobulados y cordonados $(22.7 \%)$ y cordonados $(11.4 \%){ }^{16}$

En el Centro Dermatológico Pascua se realizó un estudio retrospectivo, efectuado entre enero de 2004 y diciembre de 2011 y se encontró que $96 \%$ de los CBC se presentaron en cara y cuello, seguidos del tronco con $6 \%$, extremidades entre 0.5 y $0.6 \%$ y en genitales $0.1 \% .^{19}$

\section{COMENTARIO}

En el caso del CBC, como dermatólogos, no debemos olvidar la posibilidad de que éste pueda presentarse en una localización infrecuente, comprometiendo cualquier parte de la superficie corporal, en zonas no fotoexpuestas. Los factores que condicionan su manifestación en alguna de estas áreas son aún desconocidos. El acierto al realizar el diagnóstico depende de la sospecha clínica, por lo que, ante un posible caso, debe realizarse una biopsia incisional lo más pronto posible.

En casos de tumores pequeños, que no han iniciado su invariable curso infiltrativo, y localmente destructor, la realización de este procedimiento puede ser curativo.

En el caso comunicado en este artículo, el diagnóstico clínico inicial sugería que se trataba de un poroma ecrino. Por el tamaño de la lesión, al inicio sólo se realizó una biopsia incisional, en cuyo estudio histopatológico se observaron numerosos cordones tumorales constituidos por células basaloides, las cuales contenían pigmento melánico, se observaron también algunas cavidades; todo lo anterior se encontraba inmerso en

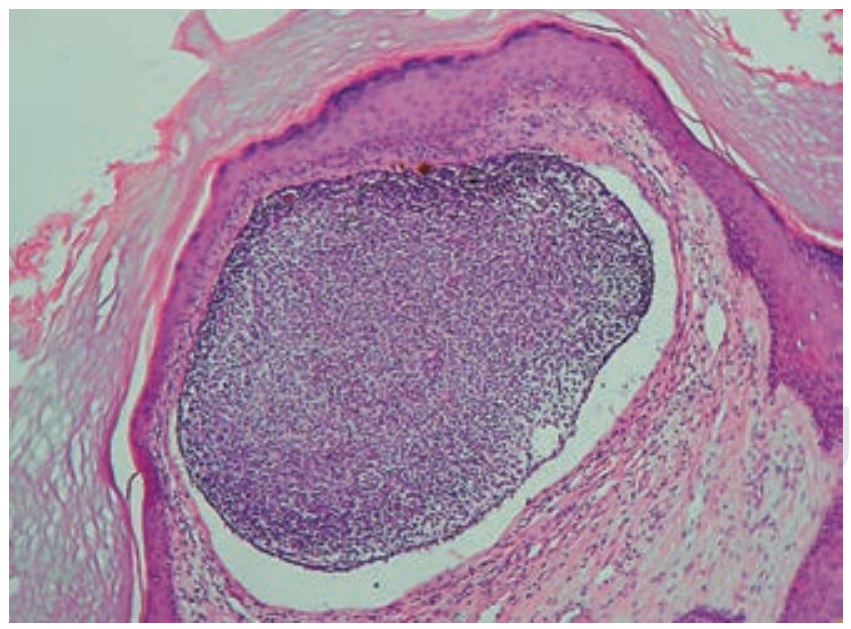

Figura 4: Neoformación exofítica cuya epidermis presenta hiperqueratosis ortoqueratósica, hipergranulosis focal y acantosis irregular moderada que alterna con áreas de atrofia (H\&E 10X).

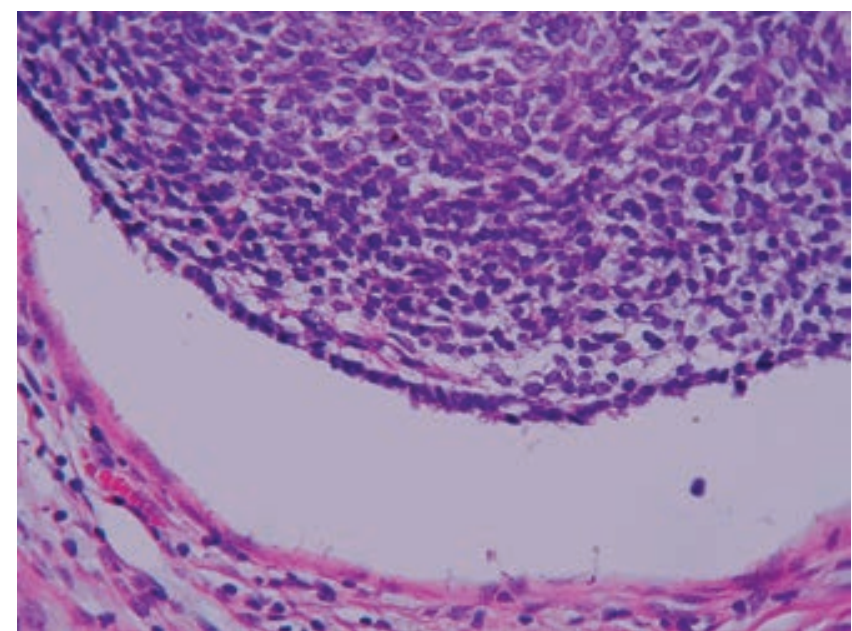

Figura 5: A mayor aumento, en el espesor de la dermis se observan numerosos cordones tumorales de células basaloides, los cuales contienen pigmento melánico, presentan algunas cavidades y están inmersos en un estroma fibroso (H\&E 40x).

un estroma fibroso, rodeado por una moderada reacción inflamatoria. Con los hallazgos observados, se realizó el diagnóstico histopatológico de carcinoma basocelular sólido quístico y pigmentado (Figuras 4 y 5).

Posteriormente, el paciente fue enviado al servicio de dermatooncología, en donde se realizó extirpación de la lesión con margen de $4 \mathrm{~mm}$. Nuevamente se envió la pieza a estudio histopatológico, el cual confirmó el diagnóstico, señalando además, que la extirpación fue completa.

En la actualidad el paciente se encuentra sin actividad tumoral, en vigilancia por dicho servicio.

La importancia de comunicar este caso, en donde la morfología y la topografía no son lo característico en un $\mathrm{CBC}$, radica en la sugerencia de que este tumor sea considerado dentro de los diagnósticos diferenciales en el caso de neoformaciones ubicadas en los sitios ya mencionados.

\section{REFERENCIAS}

Driban NE. Basaliomas de localización infrecuente. Rev Argent Dermatol. 1987; 68: 114-120.

2. Wermuth BM, Fajardo LF. Metastatic basal cell carcinoma. A review. Arch Pathol. 1970; 90: 458-462.

3. Miranda CG, Ker RS, Porto JA, Nascimento LV. Estudo das localizacoes incomuns dos epiteliomas basocelulares. An Bras Dermatol. 1992; 67: 301-304.

4. Alcalay J, Goldberg LH, Kripke ML, Wolf JE Jr. The sensitivity of Langerhans cells to simulated solar radiation in basal cell carcinoma patients. J Invest Dermatol. 1989; 93: 746-750. 
5. Chavis M, Jacobs AM, Demetri GJ Jr. Basal cell carcinoma: an infrequent pedal reality. J Foot Surg. 1989; 28: 346-351.

6. Kaufman D, Gralla R, Myskowski PL. Basal cell carcinoma: response to systemic chemotherapy for lung carcinoma. J Am Acad Dermatol. 1988; 18: 306-310.

7. Parnes R, Safai B, Myskowski PL. Basal cell carcinomas and lymphoma: biologic behavior and associated factors in sixty-three patients. J Am Acad Dermatol. 1988; 19: 1017-1023.

8. Sandstrom A, Larsson LG, Damber L. Occurrence of other malignancies in patients treated for basal cell carcinoma of the skin. A cohort study. Acta Radiol Oncol. 1984; 23: 227-230.

9. van Dam RM, Huang Z, Rimm EB, Weinstock MA, Spiegelman D, Colditz GA et al. Risk factors for basal cell carcinoma of the skin in men: results from the health professionals follow-up study. $A m \mathrm{~J}$ Epidemiol. 1999; 150: 459-468.

10. Di Fabio N, Feinsilber DG, Cha DM, Reggio SA, Avatte C, Mosca I. Epitelioma basocelular: localizaciones infrecuentes. Rev Argent Dermatol. 1986; 67: 135-138.

11. Cha DM, Feinsilber DG, Avatte C, Schroh RG. Epitelioma basocelular con diferenciación sebácea de localización infrecuente Rev Argent Dermatol. 1988; 69: 61-66.

12. Preston DS, Stern RS. Nonmelanoma cancers of the skin. $N$ Engl J Med. 1992; 327: 1649-1662.

13. Dagatti MS, Cesarios G, Feijóo FN, Martínez M. Epiteliomas basocelulares de localización infrecuente. Arch Argent Dermatol. 2006; 56: 55-58.
14. Robins P, Rabinovitz HS, Rigel D. Basal-cell carcinomas on covered or unusual sites of the body. J Dermatol Surg Oncol. 1981;7:803-806.

15. Rahbari $H$, Mehregan AH. Basal cell epitheliomas in usual and unusual sites. J Cutan Pathol. 1979; 6: 425-431.

16. Abeldaño A, Hernández Ml, Demarchi M, Pincay Cedeño L, Brea $\mathrm{P}$, Kien $\mathrm{C}$ et al. Carcinoma basocelular de localización infrecuente. Dermatol Argent. 2010; 16: 25-33.

17. Pearson G, King LE, Boyd AS. Basal cell carcinoma of the lower extremities. Int J Dermatol. 1999; 38: 852-854.

18. Carlson KC, Connolly SM, Winkelmann RK. Basal cell carcinoma on the lower extremity. J Dermatol Surg Oncol. 1994; 20: 258-259.

19. Hernández-Zárate SI, Medina-Bojórquez A, López-Tello SAL, AlcaláPérez D. Epidemiología del cáncer de piel en pacientes de la Clínica de Dermato-oncología del Centro Dermatológico Dr. Ladislao de la Pascua. Estudio retrospectivo de los últimos ocho años. Dermatol Rev Mex. 2012; 56: 30-37.

Correspondencia:

Dra. Angélica Villanueva-Otamendi

Dr. Vértiz 464, esq. Eje 3 sur,

Col. Buenos Aires, 06780,

Alcaldía Cuauhtémoc, CDMX.

Tel: 55-5538-7033

E-mail: angelica_vo@hotmail.com 